\title{
Multi-Iteration Approach to Studying Tracer Spreading Using Drifter Data
}

\author{
IRINA I. RYPINA \\ Physical Oceanography Department, Woods Hole Oceanographic Institution, Woods Hole, Massachusetts \\ DAVID FERTITTA \\ School of Oceanography, University of Washington, Seattle, Washington \\ Alison Macdonald, SAChiko Yoshida, AND SteVen JAYne \\ Physical Oceanography Department, Woods Hole Oceanographic Institution, Woods Hole, Massachusetts
}

(Manuscript received 13 July 2016, in final form 21 November 2016)

\begin{abstract}
A novel multi-iteration statistical method for studying tracer spreading using drifter data is introduced. The approach allows for the best use of the available drifter data by making use of a simple iterative procedure, which results in the statistically probable map showing the likelihood that a tracer released at some source location would visit different geographical regions, along with the associated arrival travel times. The technique is tested using real drifter data in the North Atlantic. Two examples are considered corresponding to sources in the western and eastern North Atlantic Ocean, that is, Massachusetts Bay-like and Irish Sea-like sources, respectively. In both examples, the method worked well in estimating the statistics of the tracer transport pathways and travel times throughout the entire North Atlantic. The role of eddies versus mean flow is quantified using the same technique, and eddies are shown to significantly broaden the spread of a tracer. The sensitivity of the results to the size of the source domain is investigated and causes for this sensitivity are discussed.
\end{abstract}

\section{Introduction}

\section{a. Drifter data and its usages: Global Drifter Program dataset}

Drifters are semi-Lagrangian instruments designed to follow near-surface ocean currents. They have been used by physical oceanographers for decades to study transport pathways and movements of water masses in the ocean. Generally, drifters consist of a small surface floatation device to keep the instrument afloat, and a large subsurface drogue that allows the buoy to be carried by the near-surface currents. Modern-day drifters are typically equipped with a GPS-type device that reports their geographical location on a regular schedule, thus allowing for tracking and visualization of drifter trajectories. The Global Drifter Program (GDP) database maintained and made available by National Oceanic and Atmospheric Administration (NOAA; http://www.aoml.noaa.gov/phod/dac/index.php) contains

Corresponding authore-mail: Irina I. Rypina, irypina@whoi.edu drifter data that have been accumulated over several decades of field experiments. From 1979 until present this dataset includes more than 6000 drifter trajectories in the North Pacific and more than 4500 drifter trajectories in the North Atlantic. The data coverage map for the North Atlantic is shown in Fig. 1. Here, we apply a multi-iteration approach to the North Atlantic drifter dataset to investigate and illustrate tracer spreading into the basin from various source regions.

In the remainder of the introduction, we describe the basics of a statistical approach to investigating tracer spreading, introduce the notion of probability and travel time maps, and review the so-called two-iteration method of constructing these maps using Lagrangian data. Building upon the two-iteration method, in section 2 we generalize this technique to multiple iterations. In section 3, the multi-iteration method is applied to real drifter data to study tracer spreading from two example sources, one on the western side of the North Atlantic and another on the eastern side. The role of eddies is singled out and investigated by applying the multi-iteration 


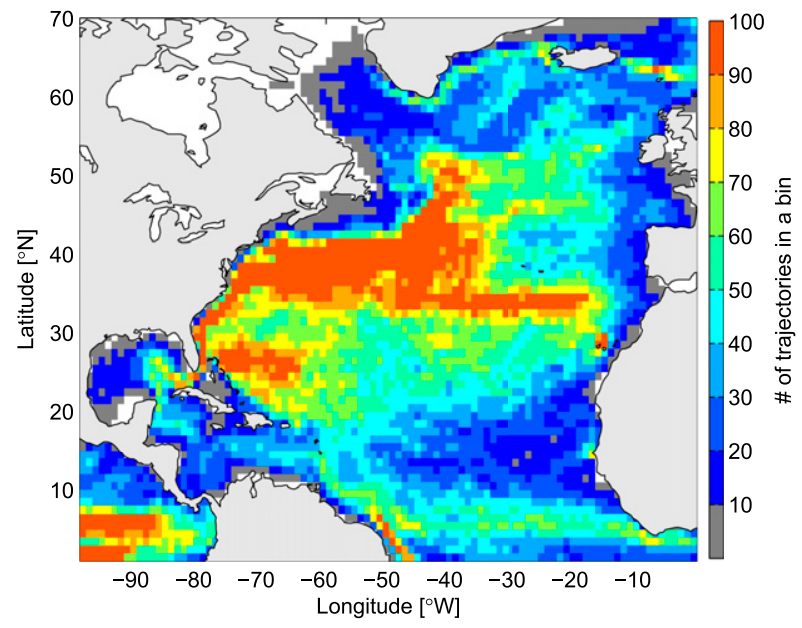

FIG. 1. For the global Drifter Program database, data coverage map showing number of trajectories passing through $1^{\circ} \times 1^{\circ}$ bins. Bins with no data are white.

technique to simulated drifter trajectories advected by a mean velocity field. There exists an alternative approach, the transfer matrix method, which also uses segments of drifter trajectories to describe the evolution of a tracer in the ocean. The transit matrix method is compared to the new multi-iteration method in section 4 , and the strengths and weaknesses of the two approaches are discussed. Section 4 also presents a summary of our results.

\section{b. Statistical approach to studying tracer spreading using drifter data (probability map-travel time map approach)}

Numerical simulation of tracer spreading in the ocean is challenging because the ocean is a highly variable environment, which means that the fate of a tracer depends on the exact timing of its release. In many cases, however, a statistically probable tracer distribution is of interest, rather than a specific tracer realization. Here, there is no intention to simulate a particular accident or true event; rather we look to illustrate the general utility of the GDP dataset for constructing a statistically robust picture of near-surface tracer spreading.

As explained in Rypina et al. (2014a, 2011), a statistically expected distribution of a tracer can be characterized by a probability map $P$ and the associated travel time map $T$. The map $P$ quantifies the probability for a water parcel originating within a specified source area to reach different geographical locations throughout the ocean. The travel time map $T$ quantifies the average time for a water parcel to get from the source to the various geographical locations. The conventional formulas for computing $P$ and $T$ are

$$
P_{i j}=\frac{N_{i j}}{N}, \quad \text { and } \quad \overline{T_{i j}}=\frac{\sum T_{i j}}{N_{i j}},
$$

where $N$ is the total number of trajectories released within the source area, $N_{i j}$ is the number of successful trajectories visiting box $i j$, and $T_{i j}$ is the time needed for each successful trajectory to reach box $i j$. We will refer to the $P$ and $T$ maps computed using Eq. (1) as the "direct" maps as they represent the statistics for a parcel to go directly from a source region to a specific location.

When a large number of drifters go through the source area, the direct $P$ and $T$ maps can produce a robust picture of tracer spreading throughout the entire ocean. Often, however, only a limited number of real drifter trajectories are available. Typically, only $O(100)$ or less are available for source areas of a few degrees in latitude and longitude that are typical for even the largest releases of hazardous material in the ocean, for example, a source representing a combination of the direct oceanic release and the main part of the atmospheric deposition of radionuclides from the 2011 Fukushima accident (see Buesseler et al. 2012; Rypina et al. 2013, 2014a). In this case, the direct $P$ and $T$ maps computed using Eq. (1) are incomplete, having a limited number of boxes with nonzero $P_{i j}$ and $T_{i j}$ and zero probabilities everywhere else.

To mitigate this problem, Rypina et al. (2014a) proposed the two-iteration method for computing $P$ and $T$ maps. In addition to drifter trajectories that pass through the source area, this approach makes use of trajectories that do not pass through the source box but instead pass through bins with nonzero $P_{i j}$. In other words, the approach treats the direct $P$ map as a distributed secondary source for a tracer. This extends the use of the dataset by allowing inclusion of "one-stop" trajectories, which consist of segments stitched together from different drifters that first connect the source A to some box $\mathrm{X}$ and then box $\mathrm{X}$ to another box B. More formally, in addition to probability $P^{\text {direct }}$ given by Eq. (1) that quantifies the percentages of trajectories going directly from the source box A to a box B, one also computes probabilities $P^{1 \text { stop }}$ defining trajectories that go from A to B with one stop at box X, as illustrated schematically in Fig. 2. The total probability to go from A to B can then be written as

$$
P^{\text {total }}=P^{\text {direct }}+P^{\text {stop }}\left(1-P^{\text {direct }}\right) .
$$

Here, the first term represents the percentage of drifters that go directly from the source A to a given box $\mathrm{B}$. The factor $\left(1-P^{\text {direct }}\right)$ is the percentage of drifters that leave 


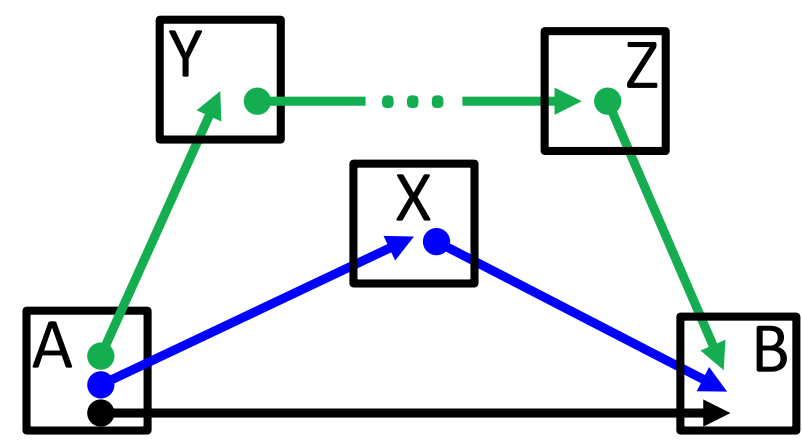

FIG. 2. Schematic diagram showing direct (black), one-stop (blue), and multistop (green) trajectories connecting the source box $\mathrm{A}$ and the receiver box $\mathrm{B}$.

the source box A but do not reach the box B. Out of those drifters, $P^{1 \text { stop }}$ percent get to the box B with one stop somewhere else within the system. Hence, the second term is the total percentage of drifters that comes out of the source box and reaches the given box with one stop. The corresponding mean travel time can be estimated as a weighted sum of the direct and one-stop travel times:

$\bar{T}_{\mathrm{A} \rightarrow \mathrm{B}}^{\text {total }}=\frac{\Sigma P T}{\Sigma P}=\frac{P_{\mathrm{A} \rightarrow \mathrm{B}}^{\text {direct }} \bar{T}_{\mathrm{A} \rightarrow \mathrm{B}}^{\text {direct }}+P_{\mathrm{A} \rightarrow \mathrm{B}}^{1 \text { stop }}\left(1-P_{\mathrm{A} \rightarrow \mathrm{B}}^{\text {direct }}\right) \bar{T}_{\mathrm{A} \rightarrow \mathrm{B}}^{1 \text { stop }}}{P_{\mathrm{A} \rightarrow \mathrm{B}}^{\text {direct }}+\left(1-P_{\mathrm{A} \rightarrow \mathrm{B}}^{\text {direct }}\right) P_{\mathrm{A} \rightarrow \mathrm{B}}^{\text {stop }}}$.

Here, as in Rypina et al. (2014a), the direct probability is

$P_{\mathrm{A} \rightarrow \mathrm{B}}^{\text {direct }}=\frac{\# \text { successful direct trajectories }}{\# \text { direct trajectories leaving } \mathrm{A}}=\frac{N_{\mathrm{A} \rightarrow \mathrm{B}}}{N_{\mathrm{A}}}$,

where $N_{\mathrm{A} \rightarrow \mathrm{B}}$ denotes the number of direct trajectories going successfully from source box A to box B, and $N_{\mathrm{A}}$ denotes the number of trajectories leaving source box A. The one-stop indirect probability is

$$
\begin{aligned}
P_{\mathrm{A} \rightarrow \mathrm{B}}^{1 \text { stop }}= & \frac{\# \text { successful one stop trajectories }}{\# \text { one stop trajectories leaving } \mathrm{A}} \\
= & \frac{\sum_{X} N_{\mathrm{A} \rightarrow \mathrm{X} \rightarrow \mathrm{B}}}{\sum_{X} N_{\mathrm{A} \rightarrow \mathrm{X} \rightarrow \text { anywhere }}}=\frac{\sum_{X} N_{\mathrm{A} \rightarrow \mathrm{X}} N_{\mathrm{X} \rightarrow \mathrm{B}}}{\sum_{X} N_{\mathrm{A} \rightarrow \mathrm{X}} N_{\mathrm{X}}},
\end{aligned}
$$

where $N_{\mathrm{A} \rightarrow \mathrm{X}}$ denotes the number of trajectories going from source box A to box $\mathrm{X}$ [the same as $N_{\mathrm{A} \rightarrow \mathrm{B}}$ in Eq. (4)], and $N_{\mathrm{X}}$ is the number of trajectories leaving box $\mathrm{X}$ after all direct trajectory segments used to construct the direct map via Eq. (4) have been removed from the dataset. This exclusion of trajectories that have already been used to estimate the direct map when computing indirect maps is required to avoid double counting. Finally, the direct travel time is
$\bar{T}_{\mathrm{A} \rightarrow \mathrm{B}}^{\text {direct }}=\frac{\sum T_{\text {successful_direct_trajectories }}}{\# \text { successful direct trajectories }}=\frac{\sum T_{\mathrm{A} \rightarrow \mathrm{B}}}{N_{\mathrm{A} \rightarrow \mathrm{B}}}$,

and the one-stop indirect travel time is

$$
\begin{aligned}
& \bar{T}_{\mathrm{A} \rightarrow \mathrm{B}}^{\text {sttop }}=\frac{\sum T_{\text {successful_direct_trajectories }}}{\# \text { successful one stop trajectories }} \\
& =\frac{\sum_{X}\left(\sum_{N_{\mathrm{A} \rightarrow \mathrm{X} \rightarrow \mathrm{B}}} T_{\mathrm{A} \rightarrow \mathrm{X} \rightarrow \mathrm{B}}\right)}{\sum_{X} N_{\mathrm{A} \rightarrow \mathrm{X} \rightarrow \mathrm{B}}} \\
& =\frac{\sum_{X}\left[\sum_{N_{\mathrm{A} \rightarrow \mathrm{X} \rightarrow \mathrm{B}}}\left(T_{\mathrm{A} \rightarrow \mathrm{X}}+T_{\mathrm{X} \rightarrow \mathrm{B}}\right)\right]}{\sum_{X} N_{\mathrm{A} \rightarrow \mathrm{X} \rightarrow \mathrm{B}}} .
\end{aligned}
$$

\section{Multi-iteration method for producing probability maps: Main idea, formulas, and numerical implementation}

The two-iteration method described above produces a more complete pair of $P$ and $T$ maps than the direct method (see Rypina et al. 2014a). However, there are usually more trajectories left in the dataset after the first iteration has been completed, and all trajectory segments used to construct one-stop trajectories have been removed. Here, we propose to generalize the two-iteration technique to include subsequent iterations, thus making the best use of the available drifter observations.

The idea is simple: we treat the total maps $P^{\text {total }}$ and $T^{\text {total }}$ resulting from the previous iteration as the input maps for producing the next iteration. In other words, we think of $P^{\text {total }}$ and $T^{\text {total }}$ as "a distributed source." Specifically, we substitute $P^{\text {total }}$ and $T^{\text {total }}$ for $P^{\text {direct }}$ and $T^{\text {direct }}$ and reapply Eqs. (2) and (3):

$$
\begin{aligned}
P_{n+1}^{\text {total }} & =P_{n}^{\text {total }}+P_{n+1}^{\text {1stop }}\left(1-P_{n}^{\text {total }}\right), \quad \text { and } \\
\bar{T}_{n+1}^{\text {total }} & =\frac{P_{n}^{\text {total }} \bar{T}_{n}^{\text {total }}+P_{n+1}^{\text {stop }}\left(1-P_{n}^{\text {total }}\right) \bar{T}_{n+1}^{\text {stop }}}{P_{n+1}^{\text {total }}},
\end{aligned}
$$

where the one-stop maps at the $n+1$ th iteration, $P_{n+1}^{1 \text { stop }}$ and $\bar{T}_{n+1}^{1 \text { stop }}$, are still given by Eqs. (5) and (7) but with $N_{\mathrm{A} \rightarrow \mathrm{X}}$ denoting the total number of trajectories going from box A to box $\mathrm{X}$ from the previous iteration (i.e., direct + with up to $\mathrm{n}$ stops), and $N_{\mathrm{X}}$ is the number of trajectories leaving box $\mathrm{X}$ in the remaining dataset after all segments used to produce $n$ previous iterations have been removed from the dataset. Similarly, at the $n+1$ th 
iteration $T_{\mathrm{A} \rightarrow \mathrm{x}}$ in the rhs of Eq. (7) is the mean travel time from the previous ( $n$ th) iteration, and $T_{\mathrm{X} \rightarrow \mathrm{B}}$ is the travel time based on the reduced dataset after all trajectory segments used at the previous iterations have been removed.

Equations (8) can be applied repeatedly until either all of the drifter data are used or until the maps converge. The number of iterations depends on the particular application and is a function of both the available data and the transport properties of the flow. In the examples considered in this paper, six iterations use all available GDP data so subsequent iterations do not cause any changes to the maps. We will come back to this point in the next section.

\section{Application to the GDP dataset in North Atlantic}

We now proceed to apply the above-described multiiteration method to real drifter data from the GDP database to investigate tracer transport pathways from two hypothetical sources of contamination in the North Atlantic Ocean. As our original studies were prompted by contamination from the Fukushima nuclear power plant (Rypina et al. 2013, 2014a) we continue in the same vein. The considered sources were motivated by the locations of two large power plants: the currently operational Pilgrim Nuclear Power Station located in Plymouth, Massachusetts, United States, and the Sellafield nuclear fuel reprocessing and nuclear decomposition site in Seascale, United Kingdom, which is currently undergoing decommission and dismantling. This choice was based entirely on scientific interest in contrasting the transport pathways from sources located on the opposite sides of the North Atlantic Ocean and not with any regard to the safety features of the two power plants themselves. They are simply example sources. There are many others that could have been chosen.

Although quite data rich on basinwide scales, the GDP dataset is not well suited for studying the small-scale nearshore circulation features and transport pathways that govern the short-term spreading of a tracer in the vicinity of a source immediately after a tracer release event. This issue is most relevant for a direct leakage scenario when, for instance, contaminants are discharged into the ocean through a pipe at a particular location, creating a delta function-like localized source. Nevertheless, once contaminants have spread to a somewhat larger $\left(100 \mathrm{~km}^{2}\right.$ or more) region, the GDP dataset becomes applicable. In the case of a power plant accident such as the March 2011 Fukushima blowout, an additional much broader secondary source of contamination was also present, which resulted from the emittance of contaminants into the atmosphere and the subsequent atmospheric fallout into the ocean with rain. The resulting spatially distributed source is usually a few hundreds of kilometers wide (Buesseler et al. 2011, 2012; Stohl et al. 2012; Rypina et al. 2013, 2014a). The GDP dataset is much better suited for addressing the corresponding large-scale tracer spreading from such an atmospheric fallout source, and we will focus on this scenario in our paper.

\section{a. Tracer spreading from a Massachusetts Bay-like source}

The Pilgrim nuclear power plant is located on the east coast of North America on the shore of Massachusetts Bay (south of Boston Harbor and north of Cape Cod Bay). The coastal currents in and around the bay are quite complicated, and the short-term dispersion of a tracer in the vicinity of the power plant would likely depend on the exact timing and wind/weather/ tidal conditions of the tracer release. The situation is further complicated by the fact that the power plant is situated roughly at the latitude of the northern boundary of Cape Cod Bay, close to a stagnation point separating fluid recirculating in the bay from fluid that bypasses the bay on the north and flows offshore. These small-scale oceanic currents and processes, which are relevant for the scenario with the direct leakage of tracer from the plant into the coastal ocean, are not resolved by the GDP dataset.

We therefore focus on investigating tracer spreading from a much larger, roughly $300 \mathrm{~km} \times 300 \mathrm{~km}$ distributed source centered at the Pilgrim power plant. A similar-sized source domain was representative of the atmospheric fallout of radionuclides that took place during the 2011 Fukushima power plant accident. This source (which is several times larger than Cape Cod Bay) contains a sufficiently large number $[O(100)]$ of trajectories that at some point in their lifetime pass through the source box so that the resulting tracer spreading pathways, quantified via $P$ and $T$ maps, are robust and insensitive to small changes in the exact placement and dimensions of the source box. We confirmed this numerically by recomputing the $P$ and $T$ maps for a slightly misplaced (half a degree, $50 \mathrm{~km}$ ) and a slightly smaller source box (that contains 50 trajectories). These calculations resulted in qualitatively similar $P$ and $T$ maps and are not shown here. In contrast, for the Irish Sea-like source located in the Irish Sea that is discussed in section 3c, the results are significantly different for a source box containing 50 versus 100 trajectories.

The first six iterations of the $P$ and $T$ maps computed using the multi-iteration method are shown in Figs. 3 

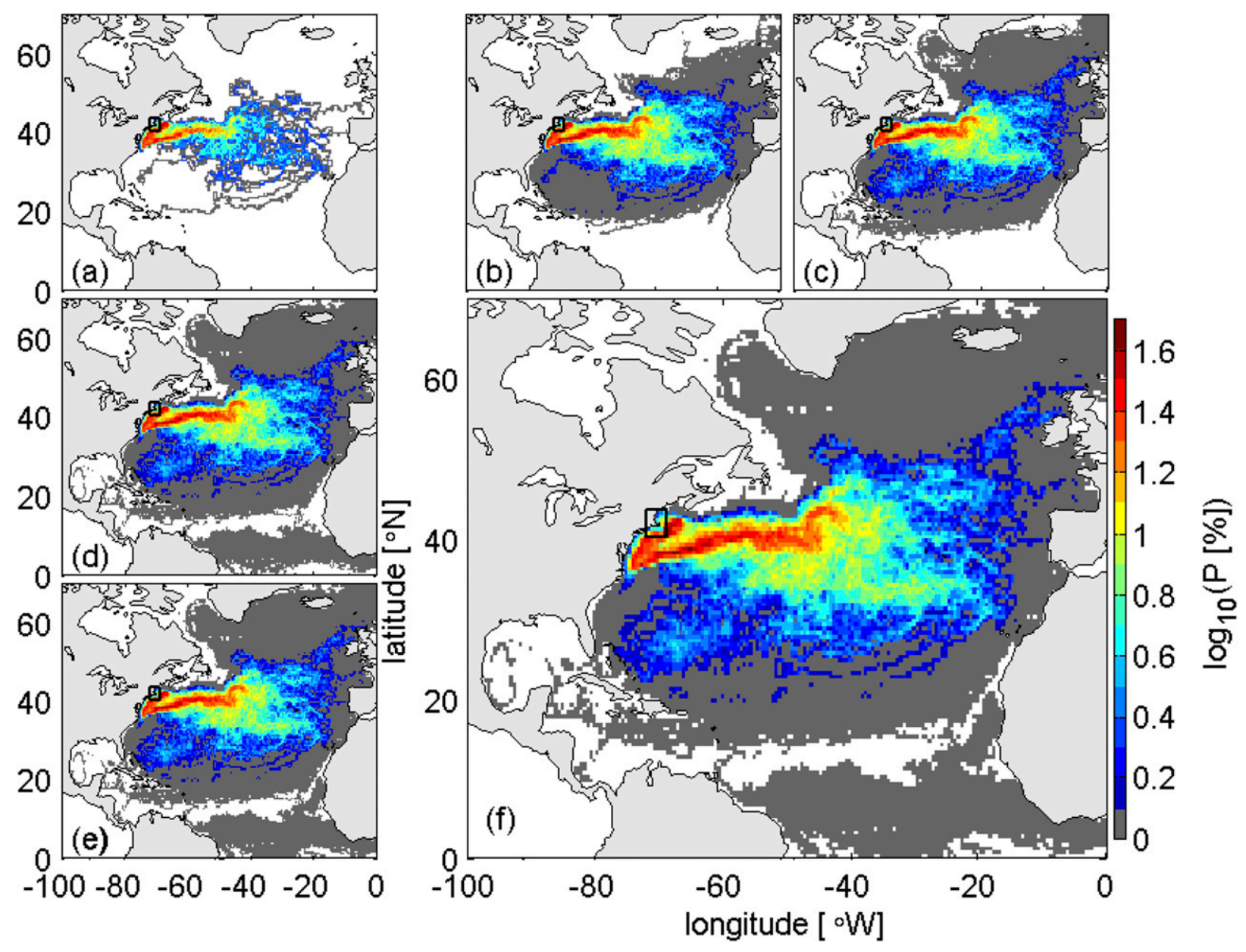

FIG. 3. For the Massachusetts Bay-like source, the (a)-(f) first six iterations of the probability map. White indicates bins with probabilities of less than $0.01 \%$; gray indicates less than roughly $1 \%$.

and 4 , respectively. The most dramatic changes occur during the first three iterations, with more subtle changes at subsequent iterations. All maps past the sixth iteration are essentially identical because by this time the vast majority of available GDP trajectory data points has been utilized and therefore removed from the dataset. This is quantified in Fig. 5, which shows the percent of unused data points remaining in the GDP dataset upon completion of the $n$th iteration.

As might be expected, the first iteration (direct) maps give a reasonable assessment of the initial spread of the tracer from the source area over the first few months but do a poor job at describing the transport pathways and travel times farther from the source. In the far field the maps become sparse and incomplete due to the limited number of trajectories passing through the source box. Nevertheless, the predominant high-probability pathway (red region emanating from the source box in Fig. 3) is already evident in the direct map, and probabilities in this region do not change significantly during subsequent iterations. The map suggests that upon spilling from Massachusetts Bay, the tracer hugs the coast and is advected southward along the shoreline until it reaches the Gulf Stream separation point near Cape Hatteras several months after its release from the source. The strong and energetic Gulf Stream Extension current flowing offshore from Cape Hatteras blocks further southward progression of the tracer (probability drops from red values north of Cape Hatteras to near zero south of Cape Hatteras) and instead diverts it offshore into the open ocean. We will refer to this high-probability pathway as the "main short-term dispersal pathway." Farther east, the Gulf Stream Extension current slows down and starts to meander, shedding eddies and large Gulf Stream rings that enhance cross-jet transport and lead to a meridional spread of the tracer plume that is seen as nonzero probabilities south of the Gulf Stream Extension current. As a result, the region of higher $P$ map values widens 

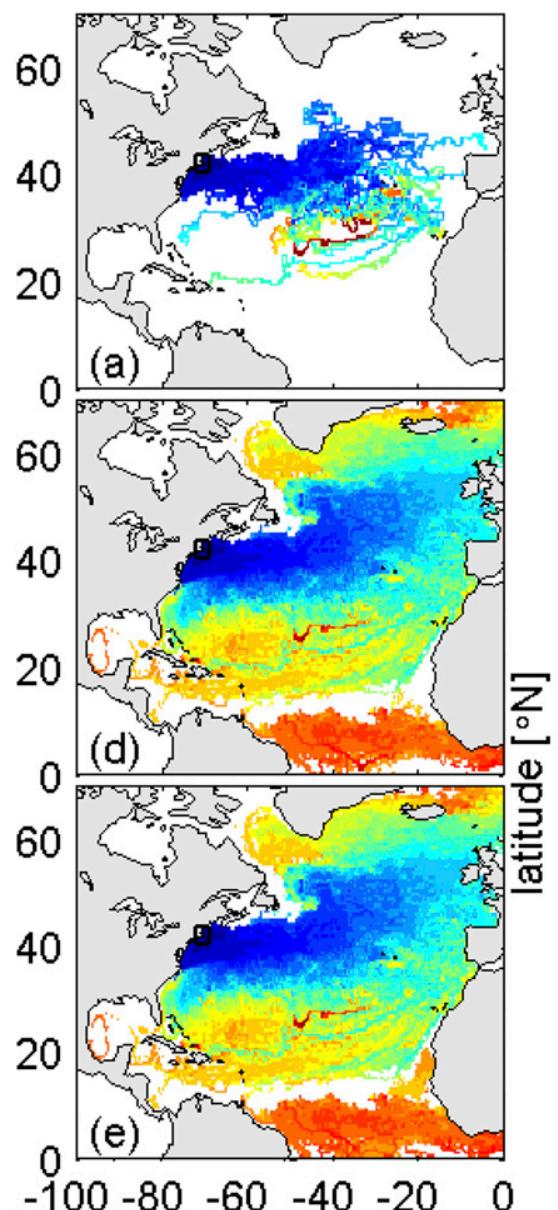
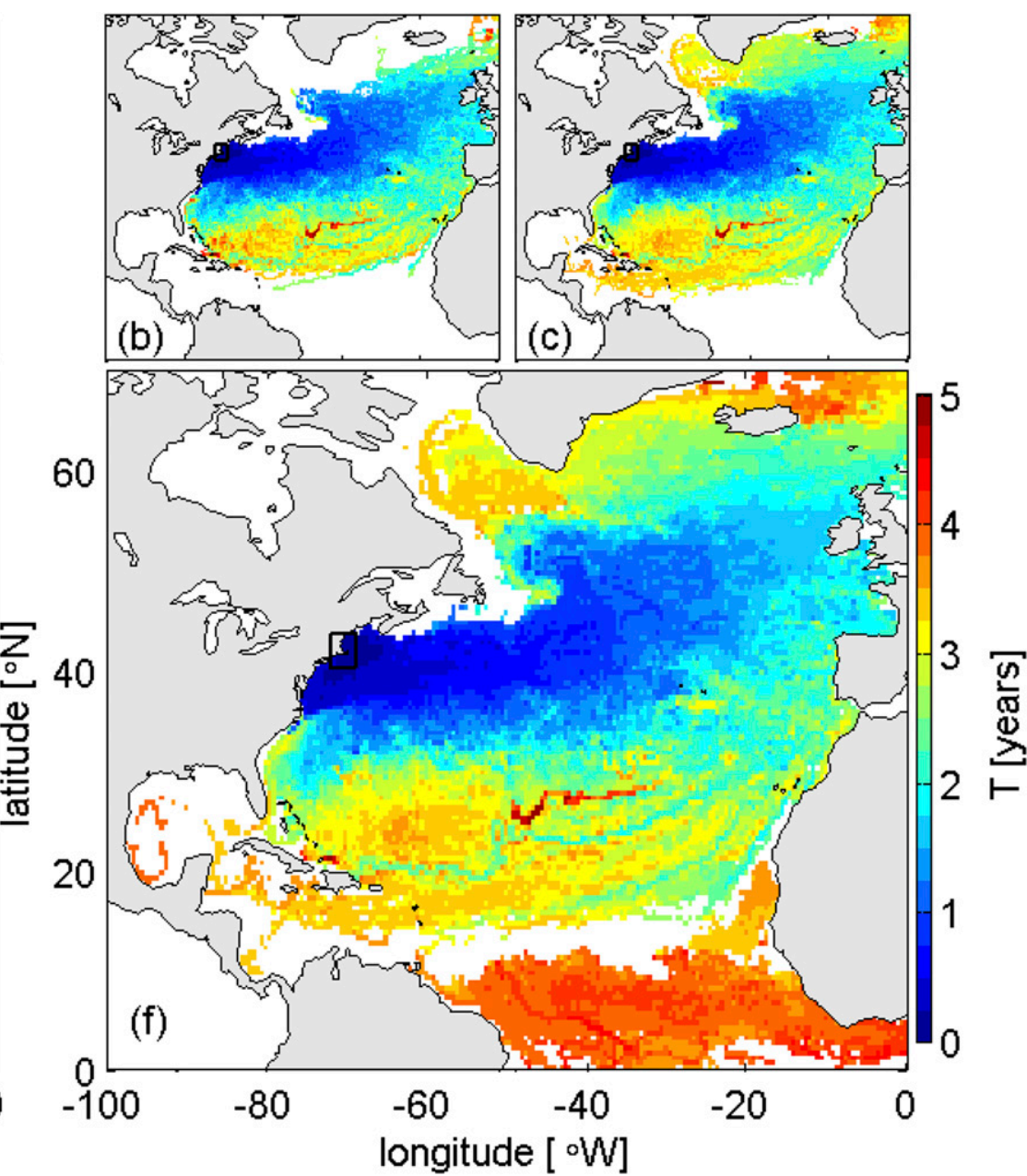

FIG. 4. For the Massachusetts Bay-like source, the (a)-(f) first six iterations of the travel time map.

substantially in the meridional direction as the tracer progresses eastward, but the probability values themselves quickly fade from red to blue and white in the eastern North Atlantic. Subsequent iterations are required to complete the maps there. There is also a hint of the subtropical gyre recirculation suggested by the direct map, but the picture is incomplete and has large gaps due to the small number of available drifter tracks used to produce this first iteration. The second iteration fills in the gaps in the eastern subtropical gyre. In this region the map (Fig. 3b) is already close to its final form, that is, it does not change much in the eastern subtropics in later iterations. The second iteration also starts to fill in the western subtropical gyre and starts to indicate the pathway bringing tracer into the subpolar gyre. But both in the western subtropics and in the subpolar region further iterations are needed to complete the map. The third iteration adds two distinct features to the map: it significantly elevates the probability values in the western subtropical gyre producing a local maximum (blue-yellow probability region) in the general area of the Sargasso Sea, where travel times are on the order of $3.5 \mathrm{yr}$; and it captures the spread of the tracer into the subpolar region. Travel times to the Irminger and Labrador Seas are about 2-3 yr, but probabilities of reaching those areas are quite small. The fourth and subsequent iterations do not lead to any significant changes in probability or travel times throughout most of the North Atlantic, except that they suggest a hint of the low-probability Loop Current pathway that brings tracer into the Gulf of Mexico roughly $3.5 \mathrm{yr}$ after the release from the source, and they indicate a small, extremely low-probability leakage of tracer from the subtropical gyre into the equatorial tropical region.

\section{b. Role of eddies in tracer dispersal}

Understanding and quantifying the effects of eddies versus mean advection on the evolution of the tracer field is key to many tracer dispersal problems (Kamenkovich et al. 2015; Rypina et al. 2012; Booth and Kamenkovich 2008; Henning and Vallis 2004; Sallee et al. 2010, 2012; 


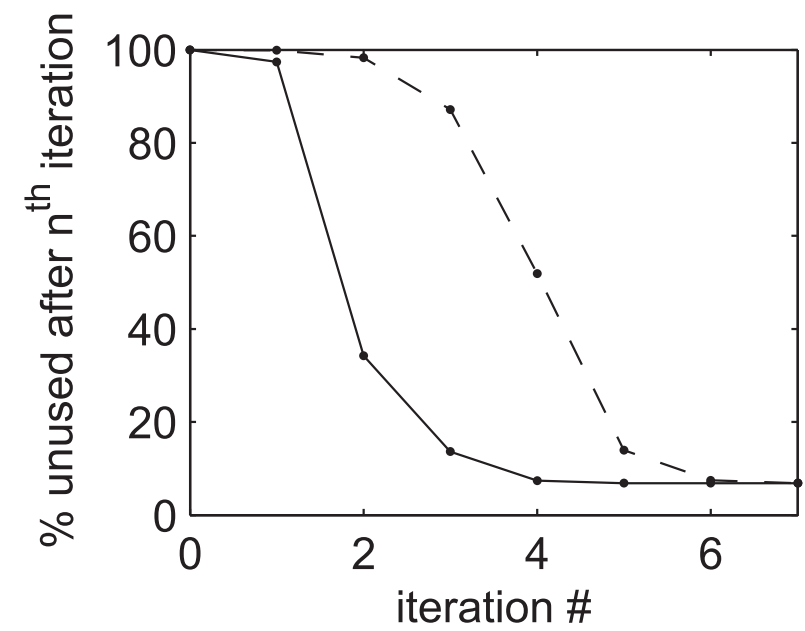

FIG. 5. The percent of unused drifter data points remaining in the dataset upon completion of $n$th iteration for the Massachusetts Bay-like source (solid) and for the Irish Sea-like source (dashed).

Naveira Garabato et al. 2011). Eddies are defined here in the most general of terms as deviations from the long-term mean. A straightforward way to address this question in the context of our study is to recompute the equivalent $P$ and $T$ maps for the mean advection case, that is, in the absence of eddies, and compare the results to the full maps in Figs. 3 and 4. The differences can then be attributed entirely to the effects of the eddy field.

To proceed with this idea, we have estimated the mean drifter-based circulation by evaluating drifter velocities using the finite-difference approach and binning and averaging drifter velocity vectors into $1^{\circ} \times 1^{\circ}$ bins. Note that although other mean velocity products are available, this method allows the analysis of the relative importance of eddies versus mean flow to be carried out using the GDP dataset alone, thereby avoid conflicting biases that might come into play through the use of additional observations or model output. The resulting mean field (Fig. 6) clearly shows the classic broad-scale North Atlantic Subtropical and Subpolar Gyres (see Koltermann et al. 2011) including all their defining circulation features: the North Equatorial Current (NEC) bringing tropical waters westward to the Caribbean Current System and the Loop Current advecting water through the Gulf of Mexico and the Florida Current flowing around the Florida Keys providing source waters for the Gulf Stream following the coast to Cape Hatteras before it turns offshore to form the Gulf Stream Extension that branches out and slows down as it leaves the coast. The wider North Atlantic Current (NAC) carries the water northeastward at about $50^{\circ} \mathrm{N}$ flowing toward the Nordic Seas. Here, in the northeast our domain cuts off. To the north, the boundary currents that flow around Greenland into the Labrador Sea are clearly illustrated

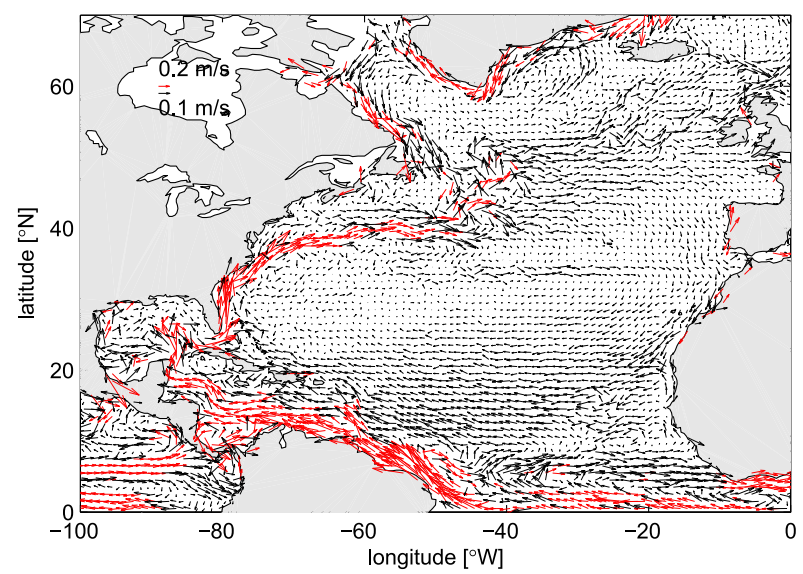

FIG. 6. Mean velocity from binned GDP drifters.

by the mean drifter-based velocity field as is the turning of the NAC southward to form the Canary Current that recirculates water clockwise through the eastern part of subtropical gyre before turning westward to join the NEC.

Using the constructed mean currents, the mean flow analog of the entire GDP drifter dataset was computed numerically by releasing simulated drifters at the release locations of real drifters and advecting them with mean velocities over the lifetimes of the real drifters. The simulated GDP dataset was then used to construct the $P$ and $T$ maps using the multi-iteration method in exactly the same manner as was done for the real GDP dataset. Figure 7 shows the resulting mean flow $P$ and $T$ maps upon completion of the sixth iteration. Comparison with the maps based on the full velocity field (Figs. 3f, 4f) suggests that the main short-term dispersal pathway that brings tracer southward along the coast to Cape Hatteras, with subsequent advection offshore just north of the Gulf Stream Extension, is due to the mean currents, as is the recirculation of tracer in the eastern part of the subtropical gyre. Not surprisingly, the pathways are narrower and stronger in the mean flow maps than in the full maps due to the absence of the eddy field (including Gulf Stream meanders and rings) that enhances meridional spreading of the tracer. Note that in the mean flow $P$ map (Fig. 7a) this pathway remains quite narrow even farther offshore where it diverges into two streams, whereas in the full flow map it "explodes" in the meridional direction at about $45^{\circ} \mathrm{W}$ due to the elevated eddy activity in this region. Travel times are generally longer for the mean flow (Fig. 7b), suggesting that eddies speed up the progression of a tracer. This is particularly true for the eastern and southern limbs of the subtropical gyre. The spreading of a tracer into the subpolar gyre is also caused by the eddies, as is the local maximum in the Sargasso Sea and leakage of tracer into the Gulf of Mexico through the Loop Current and into the Caribbean and the tropics. Note that the local 

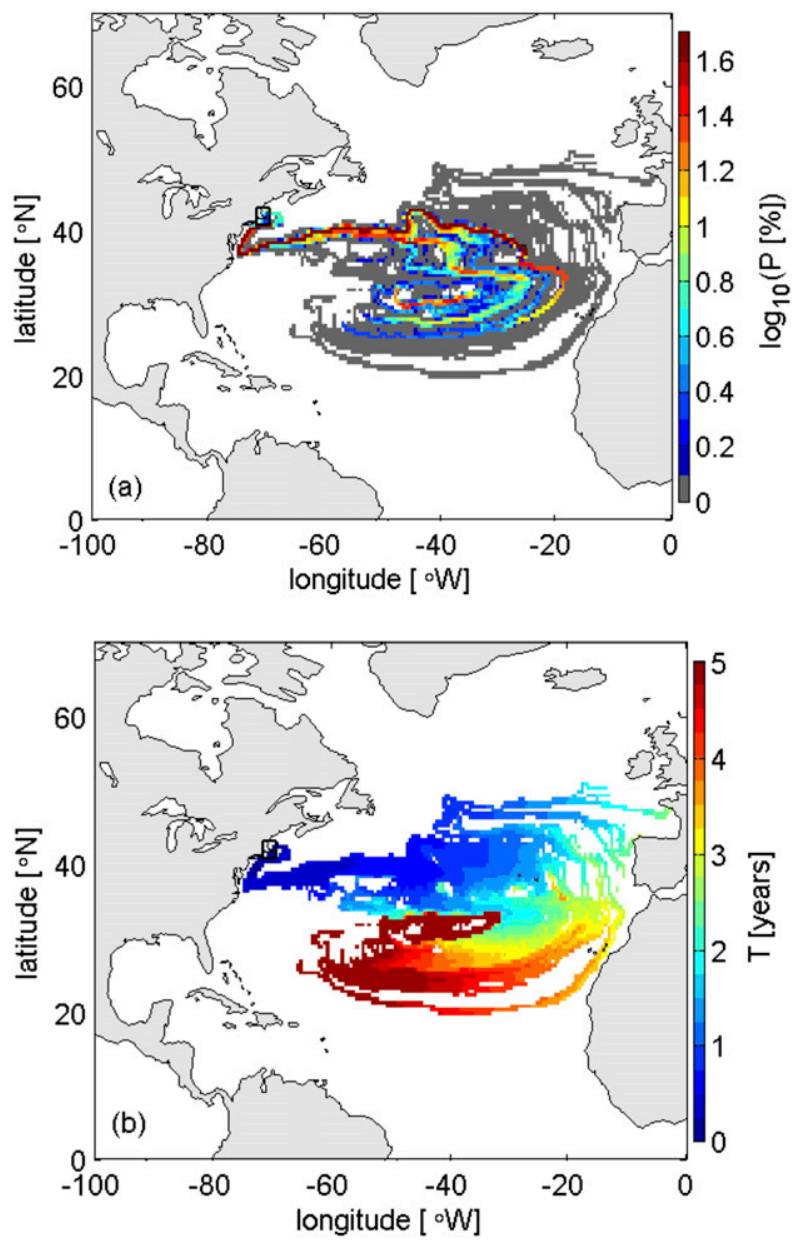

FIG. 7. (a) The mean flow analog of Fig. $3 f$ and (b) the mean flow analog of Fig. 4f.

differences between the mean and full maps are not necessarily caused by the local eddy activity but rather by the cumulative effects of eddies along the tracer path.

\section{c. Tracer spreading from an eastern Atlantic source}

We now investigate spreading of a tracer from a source in the northeastern North Atlantic. The source region in our study corresponds to the location of the Sellafield nuclear fuel reprocessing and nuclear decomposition site in Seascale, United Kingdom, situated on the coast of the Irish Sea. The Irish Sea is completely devoid of GDP drifters, but we made the source box large enough to cover segments of the North Atlantic Ocean to the north and south. The size of the source box that we used is $7.5^{\circ}$ longitude by $7.75^{\circ}$ latitude; these values represent the smallest box centered at the Sellafield location that is visited by 50 trajectories.

The first six iterations of the $P$ and $T$ maps for the Irish Sea-like source are shown in Figs. 8 and 9. As in the case of the Massachusetts Bay-like source, the maps have converged to their final form after six iterations. The nonzero probabilities cover almost the entire North Atlantic by the sixth iteration and the majority of the GDP data have been utilized by then. The reader is referred again to Fig. 5 (dashed curve), which shows the number of data points that remain in the GDP dataset upon completion of the $n$th iteration. The first and second iteration maps look pretty empty (as all 50 trajectory segments passing through the source box are quite short). By the third iteration the subpolar region has begun to fill in, and the subsequent iterations fill in the subtropical gyre as much of the interior surface waters in North Atlantic flow southward (e.g., Macdonald 1998; Cunningham et al. 2007). The final maps suggest that the highest probabilities lie to the north of the source box, where the tracer reaches after just a few months. Two other local probability maxima are seen in the subpolar gyre, which corresponds to the Irminger Current and the North Atlantic/North Atlantic Drift Currents at approximately $50^{\circ} \mathrm{N}$. A broad high-probability region is also seen in the subtropical gyre, which is associated with the Gulf Stream Extension and Canary Currents. Other areas of the North Atlantic show lower probabilities.

To understand the effect the total number of trajectories has on the result, we increase the size of the Irish Sea-like source to encompass 100 trajectories, like our first example-the Massachusetts Bay-like source in the west-and unlike the original Irish Sea-like source, which only included 50. The corresponding $P$ and $T$ maps for the 100-trajectory Irish Sea-like case (source size of roughly $9^{\circ} \times 9^{\circ}$ ) after six iterations are shown in Fig. 10. Here, instead of a predominant spreading to the north from the source region over the first few months, the tracer spreads both northward and southward leading to higher probabilities in the Bay of Biscay off the coast of France. From there, the tracer spills southward along the coast to be recirculated around the perimeter of the subtropical gyre, reach the Sargasso Sea area, and become entrained into the Gulf Stream. The tracer is then advected northward to Cape Hatteras and offshore in the Gulf Stream Extension. This process takes about 4-5 yr. Since this pathway "eats up" much of the available tracer, the probabilities are lower in the subpolar region and near the North Atlantic Current (where Fig. $8 \mathrm{f}$ had local maxima), and in the southeastern subtropical gyre, compared to the smaller source box case.

\section{Discussion and summary}

One obvious advantage of the above-described iterative procedure compared to the classic direct computation of probability maps is that it allows the use of 

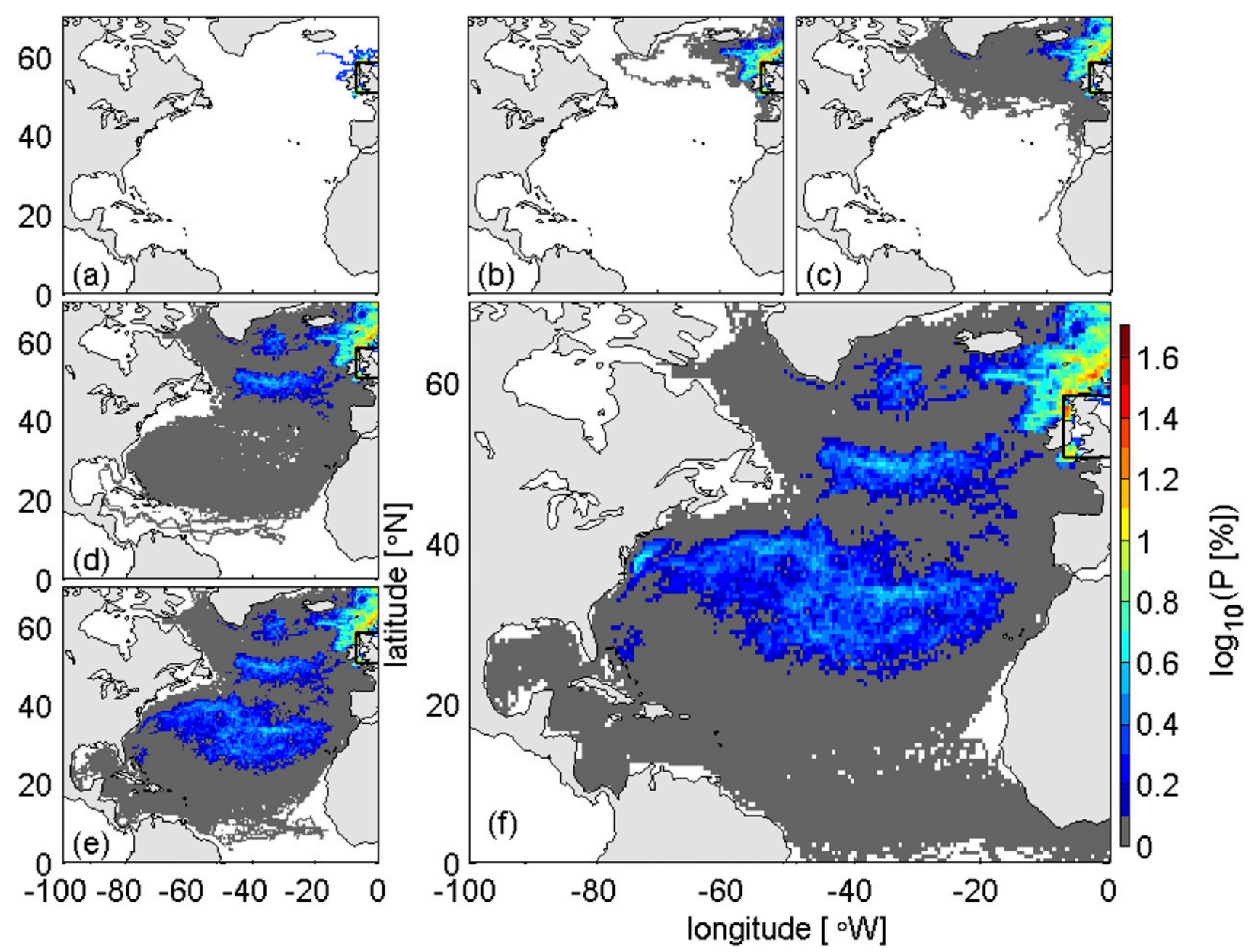

FIG. 8. As in Fig. 3, but for the Irish Sea-like source.

additional trajectory data at each subsequent iteration. The multi-iteration technique can be applied repeatedly until either all of the drifter data have been used or until the maps have converged to their limiting final form and do not change at subsequent iterations. Convergence rates and the number of required iterations depend both on the geometry and transport properties of the flow field and on the specifics of the drifter dataset.

We tested the multi-iteration method using the real drifter GDP dataset. In the two examples considered in this paper, the Massachusetts Bay-like source and the Irish Sea-like source, six iterations were sufficient for maps to converge to their final form, and changes in results are not significant for all subsequent iterations. The method worked well in both examples, producing a clear picture of the statistically probable tracer transport pathways and travel times throughout the entire North Atlantic. Additionally, we applied the same multiiteration method to simulated drifters advected by the mean flow to separate and quantify the effects of eddies versus mean advection on the resulting tracer spreading from the Massachusetts Bay-like source. For the Mass Bay-like source, there are more drifter trajectories available near the source domain than for the Irish Sealike source. As a result, for the Mass Bay-like source, the $P$ and $T$ maps are essentially the same for the source boxes that include 50 versus 100 trajectories, while for the Irish Sea-like source, the maps change significantly when the source box is increased to include 100 trajectories. It is unclear from these simulations alone whether the difference is because of the larger source region or because of the greater number of trajectories. Investigating this question would require the use of a numerical model and is left for the future study.

Note also that if one is interested in a small-scale rather than basinwide spreading of tracer, then the multi-iteration technique could just as easily be applied to study transport pathways from a smaller and more localized source of contamination, provided additional 

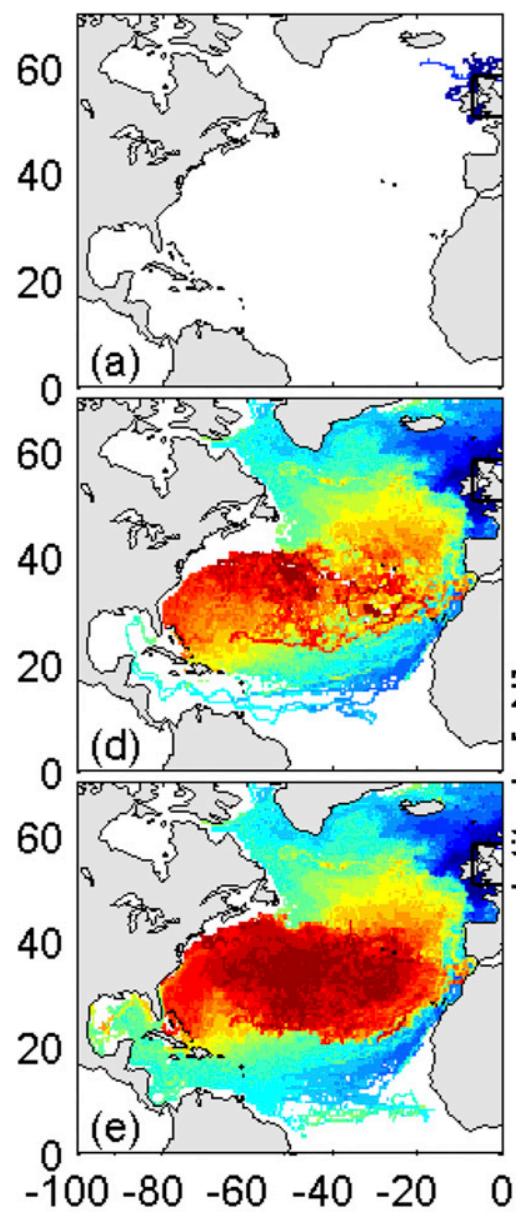
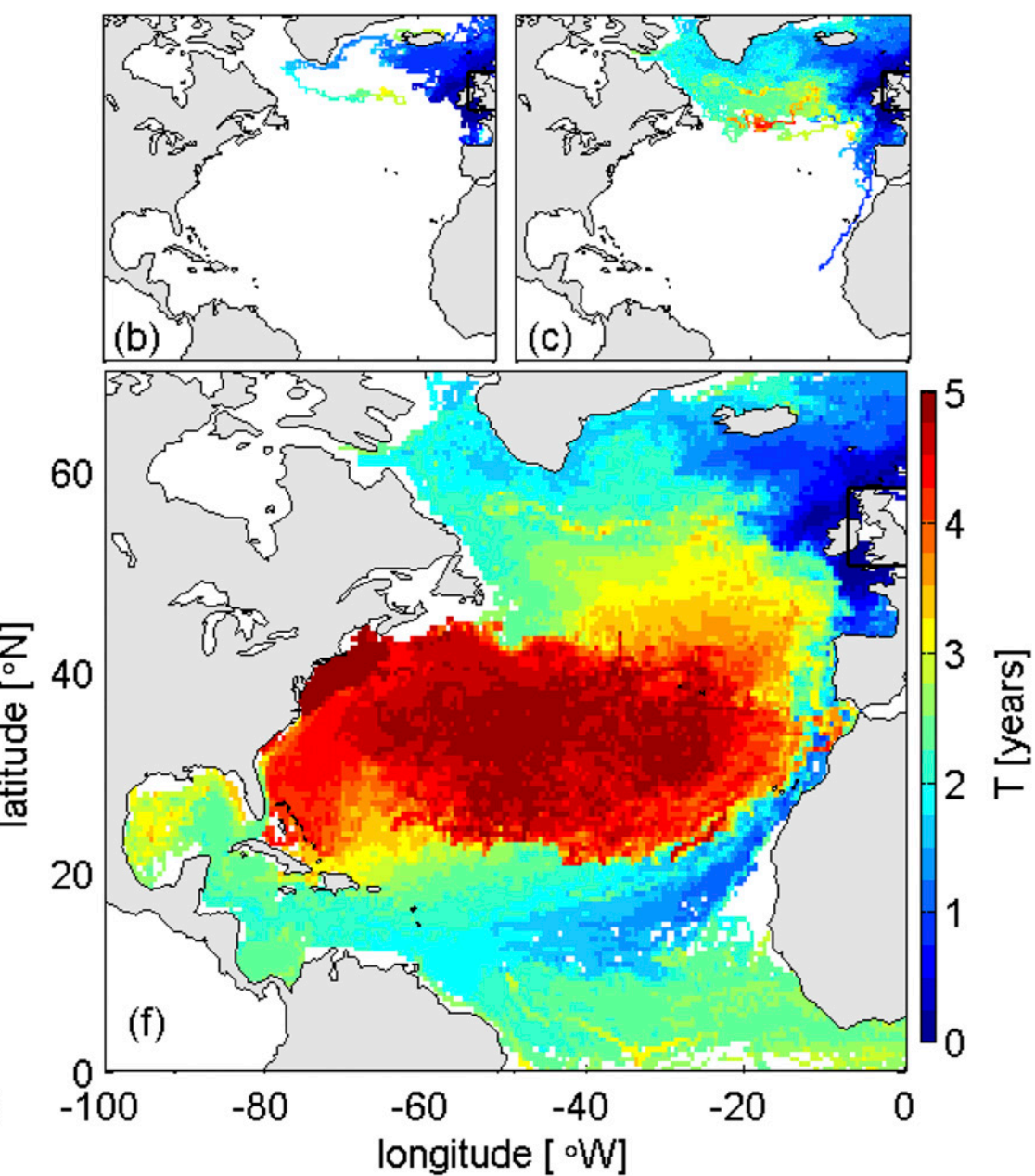

FIG. 9. As in Fig. 4, but for the Irish Sea-like source.

regional drifter datasets are available, such as, for example, Coastal Ocean Dynamics Experiment (CODE) drifters in the Cape Cod Bay and Maine coastal areas (Manning et al. 2009) or the recent deployment of drifters in the Gulf of Mexico (Olascoaga et al. 2013; Poje et al. 2014; Beron-Vera and LaCasce 2016; see also https://www.oceannews.com/news/2016/04/13/ one-thousand-drifters-and-one-future-satellite-in-thegulf-of-mexico).

The multi-iteration procedure is essentially equivalent to stitching together segments from different trajectories passing through the same geographical location to augment the drifter dataset and then using this extended dataset for computing the probability and travel time maps. One limitation of this method is that although the stitched trajectories are required to pass through the same box, they may do so at different times. Thus, a scenario is possible when two drifters pass through the "stitching box" during different seasons or vastly different weather/oceanic conditions, resulting in an unphysical piecewise continuous trajectory that does not occur in the real ocean. If there were enough data, one could add a requirement that only data from the same time period is used when stitching together segments.

The drifter-based $P$ maps characterize the 2 D nearsurface pathways for the spread of a tracer, ignoring both the three-dimensionality of the real oceanic currents and sinking of tracer particles. The usual set of limitations associated with windage and not-quiteLagrangian water-following characteristics of the nearsurface drifters also applies to our study [see Rypina et al. (2014b, 2016) for a discussion of drifter limitations]. The computed maps should be interpreted in a probabilistic sense only. Conversion from probabilities to tracer concentrations is possible for tracers with a known decay rate but was not pursued here. In this study, we used trajectories from all GDP buoys, even those that had lost their drogue at some point during their lifetime. The combined use of drogued and undrogued drifters makes our analysis potentially more 

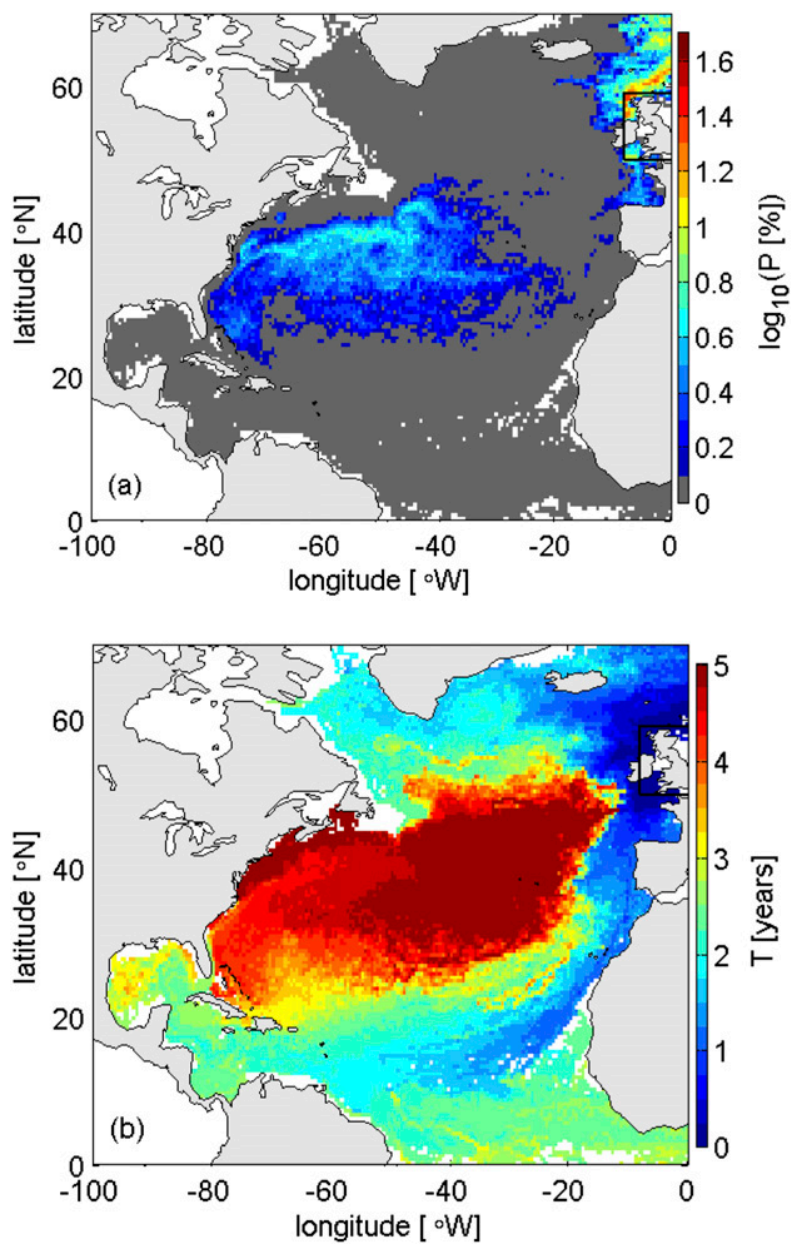

FIG. 10. (a) As in Fig. $8 \mathrm{f}$ and (b) as in Fig. 9f, but for the larger source box that includes 100 trajectories.

representative of the spreading of the surface and nearsurface debris that are not fully submerged and are directly affected by the wind blowing/pushing on components sitting above the ocean surface, rather than the spreading of chemical pollutants that are not subject to this direct windage effect.

Despite some limitations, the multi-iteration technique provides a straightforward, quantitative, and computationally efficient way to quickly assess the spreading of a tracer from any source location based on available drifter data. The same method could be applied to the subsurface float data to investigate the subsurface pathways of a tracer at depth.

Our multi-iteration statistical approach to studying tracer spreading using drifter data is similar in spirit to the transit matrix approach of van Sebille et al. (2012) and Maximenko et al. (2012); see also van Sebille et al. (2015) and Lumpkin et al. (2016). The transit matrix method uses short segments of trajectories to construct the transit matrix $\mathbf{P}^{\mathrm{TM}}$, characterizing the percentage of drifters traveling over some fixed time interval called transit time $T_{\text {transit }}$ between different grid bins of size $d x_{\text {bin }}$ by $d y_{\text {bin }}$ covering the study region. For a given initial tracer concentration distribution $n\left(t_{0}\right)$ the tracer field after time $T_{\text {transit }}$ can then be described by the matrix equation

$$
n\left(t_{0}+T_{\text {transit }}\right)=n\left(t_{0}\right) \mathbf{P}^{\mathrm{TM}},
$$

and the tracer distribution at longer times, $N T_{\text {transit }}$ with $N>1$, is given by the first $N$ iterations of the above Eq. (9). The transit time $T_{\text {transit }}$ is generally chosen to be much shorter than the average drifter lifetime, ensuring that drifter trajectories do not end in the middle of the transit time, and the box size is generally chosen to be much smaller than the size of the study domain, yielding a transit matrix $\mathbf{P}^{\mathrm{TM}}$ that is large but sparse. Maximenko et al. (2012) used $T_{\text {transit }}=5$ days and $d x_{\text {bin }}=d y_{\text {bin }}=0.5^{\circ}$.

The main difference between the transit matrix method and the multi-iteration approach presented in this paper is that we use the entire trajectory of each drifter passing through the source box to produce the first iteration of $P$ and $T$. We then use the entire trajectory (with elimination to avoid double counting) of each drifter passing through the respective nonempty $P$ boxes (our secondary sources) to construct the subsequent iterations of $P$ and $T$. Loosely speaking, we place greater value on the long direct trajectories of drifters passing through the initial source box and only improve upon the resulting maps by stitching these direct trajectories to others. In contrast, the transit matrix method treats all trajectories (long and short, passing through the original source box or not) the same. It splits them into short segments and stitches all of them together, placing equal value on each. As a consequence, the transit matrix approach produces smoother results because it is more diffusive. It is also subject to unrealistically large cross-frontal tracer spreading when trajectory segments on opposite sides of the front or jet are stitched together (as illustrated by Fig. 11). This effect becomes more severe as the bin size increases and transit times decrease. The effect can be quantified by introducing an artificial equivalent diffusivity, $K \sim\left(d x_{\text {bin }} \times d y_{\text {bin }}\right) / T_{\text {transit }}$ that enhances tracer spreading. In contrast to the transit matrix approach, which depends on two free parameters, grid bin size, and transit time, our multi-iteration method depends only on bin size.

A comparison between the transit matrix method and the multi-iteration method for the Massachusetts Baylike source is shown in Fig. 11. The three bottom subplots were extracted directly from Figs. $3 \mathrm{f}$ and $4 \mathrm{f}$ by plotting probabilities $P_{i j}$ from Fig. 3f in those bins $(i, j)$, where the corresponding mean travel time $T_{i j}$, from 


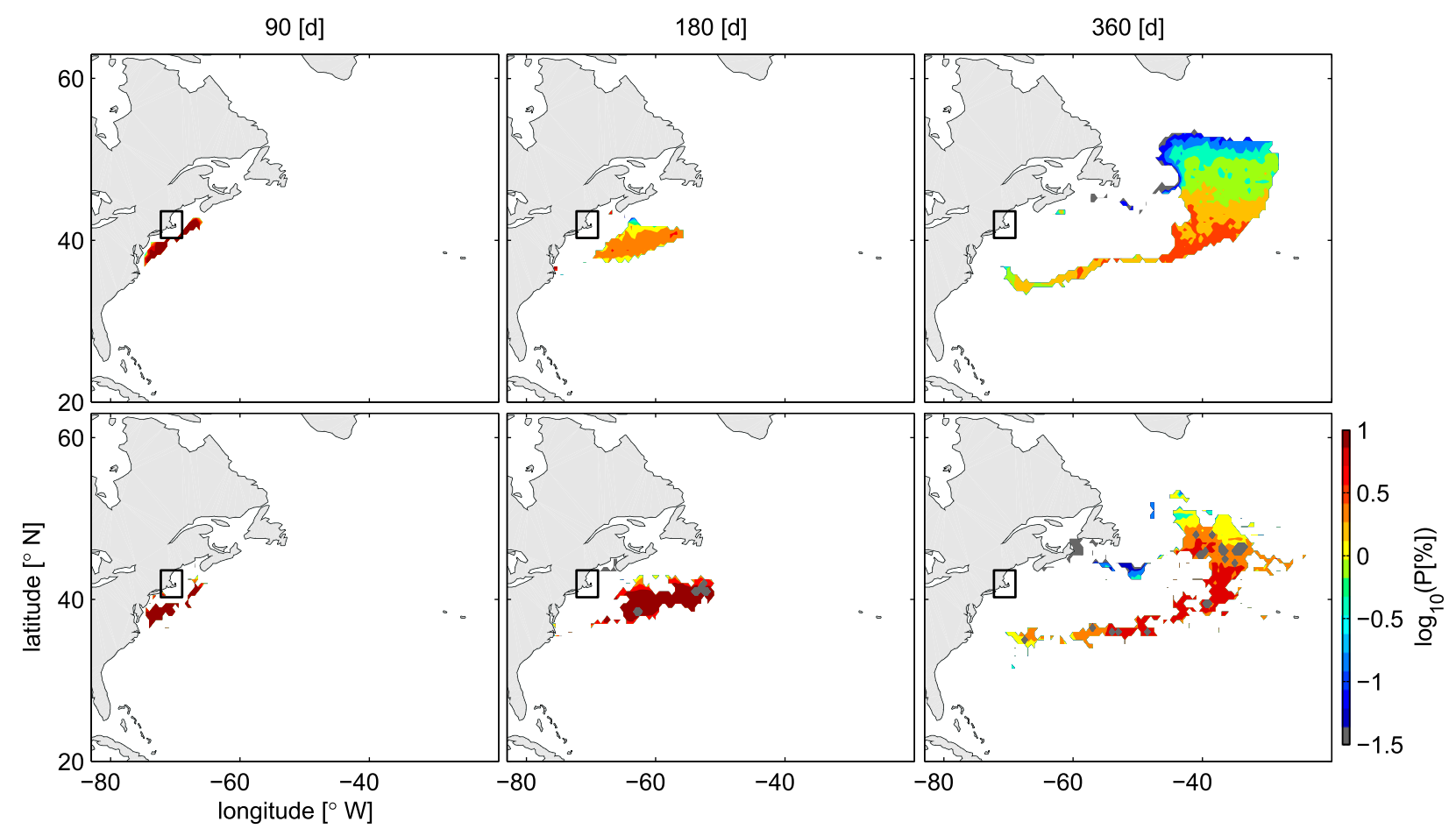

FIG. 11. Comparison between the (top) transit matrix method and (bottom) multi-iteration method for the Massachusetts Bay-like source.

Fig. 4f, is equal to 90,180 , and 360 days, respectively. We remind the reader that $P_{i j}$ quantifies the probability for a particle released within the Massachusetts Bay-like source to pass through the bin $(i, j)$.

To construct a similar map using the transit matrix method, the following procedure was applied. First, the transit matrix was constructed using all GDP trajectories in the North Atlantic with the same parameter choices as in Maximenko et al. (2012), that is, $T_{\text {transit }}=5$ days and $d x_{\text {bin }}=d y_{\text {bin }}=0.5^{\circ}$. The matrix equation [(9)] was iteratively evolved for $5 \mathrm{yr}$ starting with the initial tracer distribution $n\left(t_{0}\right)$ corresponding to the Massachusetts Bay-like source, that is, uniform initial tracer distribution, $n\left(t_{0}\right)=1 / A_{\text {source}}$, where $A_{\text {source }}$ is the source box area, within the source box and zero values, $n\left(t_{0}\right)=0$, outside. The resulting tracer distributions $n(t)$ were normalized to 1 after each iteration to ensure tracer conservation. Next, the mean travel time from the source box to each grid bin $(i, j)$ was computed as a weighted sum:

$$
T_{i j}^{\mathrm{TM}}=\frac{\sum_{N} N T_{\text {transit }} n_{i j}\left(t_{0}+N T_{\text {transit }}\right)}{\sum_{N} n_{i j}\left(t_{0}+N T_{\text {transit }}\right)},
$$

where $N$ is the iteration number, and the associated probability for a tracer to visit a grid bin $(i, j)$ was computed by summing all tracer concentrations in that bin: $P_{i j}^{\mathrm{TM}}=\sum_{N} n_{i j}\left(t_{0}+N T_{\text {transit }}\right)$. Here, the superscript TM denotes the transit matrix method to distinguish it from the multi-iteration-based $P$ and $T$. Since the total amount of released tracer is $1, P_{i j}^{\mathrm{TM}}$ can be interpreted as the total probability for a tracer released within the Massachusetts Bay-like source to visit bin $(i, j)$. Finally, to produce the top three panels of Fig. 11, we extracted and plotted the transit matrix-based probabilities $P_{i j}^{\mathrm{TM}}$ in those bins $(i, j)$, where the corresponding transit matrix-based mean travel time $T_{i j}^{\mathrm{TM}}$, from Eq. (10), is equal to 90,180 , and 360 days, respectively.

Overall, both methods consistently indicate the steady eastward progression of the tracer over the first year, and the methods agree on the general location and extent of the tracer plume. However, compared to the transit matrix method, the multi-iteration method predicts slightly larger probabilities or, equivalently, larger tracer concentrations occupying a slightly smaller geographical domain, which is evident in the two right subplots of Fig. 11. The transit matrix method, on the other hand, produces a smoother, slightly wider, and less concentrated probability distribution. Interestingly, though perhaps not surprisingly, the westernmost tail of the transit matrix-based probability distribution in the top-right panel of Fig. 11 penetrates farther south through the core of the Gulf Stream compared to the multi-iteration prediction in the bottom-right panel of Fig. 11, indicating stronger cross-jet spreading for the 
transit matrix approach. These effects are in agreement with the general expectations described above that the transit matrix method is more diffusive than the multiiteration method.

It is interesting to think about the potential advantages of a hybrid approach, where the multi-iteration method is used to determine the optimal transit time $T$ and to produce an improved estimate of the transit matrix $\mathbf{P}^{\mathrm{TM}}$, which can then be iterated according to Eq. (9) to produce tracer distributions at longer times. This development is left for future study and is not pursued further in this paper.

Acknowledgments. This work was supported by the Grant OCE-1356630 from the National Science Foundation (NSF). Rypina also acknowledges NSF Grant OCE-1154641 and NASA Grant NNX14AH29G. Macdonald acknowledges the efforts of three Falmouth Academy high school students, Ethan Altshuler, Robert Eder, and Megan Flory, whose science fair projects investigating the fate of contamination from a hypothetical Fukushima-like accident at the Plymouth, Massachusetts, power plant provided some preliminary results for Fertitta and motivated the current research. We also acknowledge the WHOI Summer Student Fellow program that supported Fertitta.

\section{REFERENCES}

Beron-Vera, F. J., and J. H. LaCasce, 2016: Statistics of simulated and observed pair separations in the Gulf of Mexico. J. Phys. Oceanogr., 46, 2183-2199, doi:10.1175/JPO-D-15-0127.1.

Booth, J., and I. Kamenkovich, 2008: Isolating the role of transient mesoscale eddies in mixing of a passive tracer in an eddy resolving model. J. Geophys. Res., 113, C05021, doi:10.1029/ 2007JC004510.

Buesseler, K. O., M. Aoyama, and M. Fukasawa, 2011: Impacts of the Fukushima nuclear power plants on marine radioactivity. Environ. Sci. Technol., 45, 9931-9935, doi:10.1021/es202816c.

— , and Coauthors, 2012: Fukushima-derived radionuclides in the ocean and biota off Japan. Proc. Natl. Acad. Sci. USA, 109, 5984-5988, doi:10.1073/pnas.1120794109.

Cunningham, S. A., and Coauthors, 2007: Temporal variability of the Atlantic meridional overturning circulation at $26.5^{\circ} \mathrm{N}$. Science, 317, 935-938, doi:10.1126/science.1141304.

Henning, C. C., and G. Vallis, 2004: The effects of mesoscale eddies on the main subtropical thermocline. J. Phys. Oceanogr., 34, 2428-2443, doi:10.1175/JPO2639.1.

Kamenkovich, I., I. I. Rypina, and P. Berloff, 2015: Properties and origins of the anisotropic eddy-induced transport in the North Atlantic. J. Phys. Oceanogr., 45, 778-791, doi:10.1175/ JPO-D-14-0164.1.

Koltermann, K. P., V. V. Gouretski, and K. Jancke, 2011: Atlantic Ocean. Vol. 3, Hydrographic Atlas of the World Ocean Circulation Experiment (WOCE), M. Sparrow, P. Chapman, and J. Gould, Eds., International WOCE Project Office, 174 pp.

Lumpkin, R., L. Centurioni, and R. Perez, 2016: Fulfilling observing system implementation requirements with the global drifter array. J. Atmos. Oceanic Technol., 33, 685-695, doi:10.1175/JTECH-D-15-0255.1.

Macdonald, A. M., 1998: The global ocean circulation: A hydrographic estimate and regional analysis. Prog. Oceanogr., 41, 281-382, doi:10.1016/S0079-6611(98)00020-2.

Manning, J. P., D. J. McGillicuddy Jr., N. R. Pettigrew, J. H. Churchill, and L. S. Incze, 2009: Drifter observations of the Gulf of Maine coastal current. Cont. Shelf Res., 29, 835-845, doi:10.1016/j.csr.2008.12.008.

Maximenko, N. A., J. Hafner, and P. P. Niiler, 2012: Pathways of marine debris derived from trajectories of Lagrangian drifters. Mar. Pollut. Bull., 65, 51-62, doi:10.1016/j.marpolbul.2011.04.016.

Naveira Garabato, A. C., R. Ferrari, and K. L. Polzin, 2011: Eddy stirring in the Southern Ocean. J. Geophys. Res., 116, C09019, doi:10.1029/2010JC006818.

Olascoaga, M. J., and Coauthors, 2013: Drifter motion in the Gulf of Mexico constrained by altimetric Lagrangian coherent structures. Geophys. Res. Lett., 40, 6171-6175, doi:10.1002/ 2013 GL058624.

Poje, A. C., and Coauthors, 2014: Submesoscale dispersion in the vicinity of the Deepwater Horizon spill. Proc. Natl. Acad. Sci. USA, 111, 12 693-12 698, doi:10.1073/pnas.1402452111.

Rypina, I. I., L. J. Pratt, and M. S. Lozier, 2011: Near-surface transport pathways in the North Atlantic Ocean. J. Phys. Oceanogr., 41, 911-925, doi:10.1175/2011JPO4498.1.

—, I. Kamenkovich, L. J. Pratt, and P. Berloff, 2012: Eddyinduced particle dispersion in the North Atlantic. J. Phys. Oceanogr., 42, 2206-2228, doi:10.1175/JPO-D-11-0191.1.

- S. Jayne, S. Yoshida, A. Macdonald, E. Douglass, and K. Buesseler, 2013: Short-term dispersal of Fukushimaderived radionuclides off Japan: Modeling efforts and model-data intercomparison. Biogeosciences, 10, 4973-4990, doi:10.5194/bg-10-4973-2013.

_ S. R. Jayne, S. Yoshida, A. M. Macdonald, and K. Buesseler, 2014a: Drifter-based estimate of the 5 year dispersal of Fukushima-derived radionuclides. J. Geophys. Res. Oceans, 119, 8177-8193, doi:10.1002/2014JC010306.

, A. Kirincich, R. Limeburner, and I. A. Udovydchenkov, 2014b: Eulerian and Lagrangian correspondence of high-frequency radar and surface drifter data: Effects of radar resolution and flow components. J. Atmos. Oceanic Technol., 31, 945-966, doi:10.1175/JTECH-D-13-00146.1.

, — - S. Lentz, and M. Sundermeyer, 2016: Investigating the eddy diffusivity concept in the coastal ocean. J. Phys. Oceanogr., 46, 2201-2218, doi:10.1175/JPO-D-16-0020.1.

Sallee, J.-B., K. Speer, S. Rintoul, and S. Wijffels, 2010: Southern Ocean thermocline ventilation. J. Phys. Oceanogr., 40, 509529, doi:10.1175/2009JPO4291.1.

— R. Matear, A. Lenton, and S. R. Rintoul, 2012: Localized subduction of anthropogenic carbon dioxide in the Southern Hemisphere oceans. Nat. Geosci., 5, 579-584, doi:10.1038/ngeo1523.

Stohl, A., and Coauthors, 2012: Xenon-133 and caesium-137 releases into the atmosphere from the Fukushima Dai-ichi nuclear power plant: Determination of the source term, atmospheric dispersion, and deposition. Atmos. Chem. Phys., 12, 2313-2343, doi:10.5194/acp-12-2313-2012.

van Sebille, E., M. H. England, and G. Froyland, 2012: Origin, dynamics and evolution of ocean garbage patches from observed surface drifters. Environ. Res. Lett., 7, 044040, doi:10.1088/ 1748-9326/7/4/044040.

_ , and Coauthors, 2015: A global inventory of small floating plastic debris. Environ. Res. Lett., 10, 124006, doi:10.1088/ 1748-9326/10/12/124006. 